This is a self-archived - parallel published version of this article in the publication archive of the University of Vaasa. It might differ from the original.

\title{
Smart Control of Battery Energy Storage System in Harbour Area Smart Grid: A Case Study of Vaasa Harbour
}

Author(s): Kumar, Jagdesh; Khan, Hussain Sarwar; Kauhaniemi, Kimmo

Title: $\quad$ Smart Control of Battery Energy Storage System in Harbour Area Smart Grid: A Case Study of Vaasa Harbour

Year: $\quad 2021$

Version: Accepted manuscript

Copyright (C)2021 IEEE. Personal use of this material is permitted. Permission from IEEE must be obtained for all other uses, in any current or future media, including reprinting/republishing this material for advertising or promotional purposes, creating new collective works, for resale or redistribution to servers or lists, or reuse of any copyrighted component of this work in other works.

Please cite the original version:

Kumar, J., Khan, H. S. \& Kauhaniemi, K. (2021). Smart Control of Battery Energy Storage System in Harbour Area Smart Grid: A Case Study of Vaasa Harbour. IEEE EUROCON 2021 - 19th International Conference on Smart Technologies, 21141251. IEEE.

https://doi.org/10.1109/EUROCON52738.2021.9535557 


\section{Smart Control of Battery Energy Storage System in Harbour Area Smart Grid: A Case Study of Vaasa Harbour}

\author{
Jagdesh Kumar \\ School of Technology and Innovations \\ University of Vaasa \\ Vaasa, Finland \\ jagdesh.kumar@uwasa.fi
}

\author{
Hussain Sarwar Khan \\ School of Technology and Innovations \\ University of Vaasa \\ Vaasa, Finland \\ hussain.khan@uwasa.fi
}

\author{
Kimmo Kauhaniemi \\ School of Technology and Innovations \\ University of Vaasa \\ Vaasa, Finland \\ kimmo.kauhaniemi@uwasa.fi
}

\begin{abstract}
Battery energy storage system plays an essential role for optimally controlling and managing power of modern harbour grids so as to support electric vessels requiring onshore power supply and battery charging system. Designing an appropriate size of battery energy storage system of any harbour grid require precise data of power consumption as well future planned load. This paper presents a practical approach where a charge/discharge strategy is applied in such a way that peak-load demand of harbour grid is shaved off by discharging the battery during peak demand load and charging it during offpeak load demand. A suitable battery energy storage system along with its control algorithm is designed for Vaasa harbour grid with the obtained real data of annual power consumption and available power resources. Vaasa harbour grid model is developed in MATLAB/Simulink and a control algorithm is developed for the power flow to and from battery energy storage system by charging and discharging through bi-directional dcdc converter. The results show that battery energy storage system is a suitable solution for harbour grids to cope with growing demand of new electric ships optimally in harbour grid without extensive renovation of the power supply infrastructure.
\end{abstract}

Keywords- Battery energy storage system, Harbour grid, Microgrid, Onshore power supply, Power control

\section{INTRODUCTION}

Seagoing vessels play a crucial role in global trade [1], but mostly they employ cheap quality fossil fuel for power generation from diesel engines onboard. The major issues concerning modernizing these vessels are to reduce environmental pollutions while maneuvering as well as staying at berth [2], saving fuel, and increasing energy efficiency [3]. These problems can be well tackled in harbours with power being supplied from microgrid consisting of renewable energy sources, and battery energy storage system (BESS) in parallel with main grid power supply. In this regard, the concept of harbour area smart grid (HASG) [4][5], has been proposed recently in the literature, which can support onshore power supply as well as charging of batteries for the modern vessels [6].

The process of shutting down auxiliary diesel engines of ships and obtaining an onshore power supply for the ships' auxiliary services during a stay in port is historically termed 'cold-ironing' or 'onshore power supply' or 'shore-to-ship power' [5][7]. The HVSC standard [8] has been developed and unanimously adopted by world leading organisations, namely the IEC, ISO and IEEE, for promoting shore-to-ship power supply. Shore-to-ship power supply is an emerging paradigm [9], and it has been observed that the shore-to-ship power can reduce $\mathrm{CO} 2$ emissions significantly at harbours
[10]. The European Directives also force the ships to use either low-sulphur fuel for onboard power generation in vessels or onshore power supply while staying at harbours to curb greenhouse gas emissions, air and noise pollutions [11]. The shore-to-ship power should be supplied by a near zero or emission-free power generation sources and smart grids having electric power generation from multiple renewable sources (wind, photovoltaic, etc.) nearby harbours along with utility power supply can provide economical as well as clean energy for onshore power supply [4][12]. Moreover, use of energy storage at harbours can reduce air emissions as well as facilitate the power generation with respect to optimal load scheduling [13][14]. A BESS employed by modern vessels needs to be recharged after reaching a certain depth of discharge. The concept of harbour area smart grid (HASG) [4][5] and seaport microgrids [15] aims to coordinate multiple renewable energy resources along with main grid supply to optimally balance power and energy requirements of hybrid and electric vessels requiring shore-to-ship power supply, battery charging stations, and other necessary loads at harbours.

There are several challenges for the HASG such as balancing of power for the distributed energy resources (DERs) inside the microgrid during grid-connected mode, islanding detection of a microgrid, and smooth transition of microgrid from grid-connected to islanded mode [16]. It is also required to maintain the voltage and frequency for onshore power supply according to the High Voltage Shore Connection (HVSC) standards [8]. Besides these challenges, harbours will require significantly higher amount of power and energy consumption in future especially because of need of onshore power supply, and battery charging stations of modern electric ships. The power consumption and schedule of each vessel arriving at and leaving from harbour is different, therefore power and energy consumption of a harbour can be optimized in such a way that peak-load load demand can be shaved off. Thus, future harbour grids will require suitable objective functions to design harbour grid in such a way that losses are minimized, and the available resources are operated and controlled efficiently and economically. Therefore, it is necessary to design a harbour grid optimally so that electric power and energy can be efficiently utilised while managing electric power supply and consumption according to the needs of harbour operations and availability of renewable energy resources. The various types of battery technologies, such as lead-acid, lithium-ion, and redox-flow have been employed in various harbour grids depending up on specific power and energy requirements load profiles [17]. 
The objective of the paper is to develop a control algorithm for battery energy storage system in harbour grids in such a way that power and energy consumption can be economically and efficiently fulfilled with the available energy resources. Essentially the applied approach is suitable to avoid capital cost of installing extra power system infrastructure in harbour grids to meet the peak-load demand. As a case study the real data from Vaasa harbour is applied which is currently being renovated with shore-to-ship power supply available for a new hybrid electric system based ferry Aurora Botnia. The optimization target is achieved by developing a simulation model of Vaasa harbour grid with hourly data of annual power consumption of various loads and suitable optimization techniques is applied to control the charge/discharge characteristics of battery energy storage system. These charge/discharge characteristics are decisive in designing a proper size of battery energy storage system, reducing peakload demand of a harbour, avoid expansion of transmission line. Thus, harbour grids behaving as a microgrid will have more flexibility to manage power optimally in such a way that exchange of power between ports and ships will also be possible.

The rest of the paper is organised as follows. Section II presents the detailed single line diagram of feeder topology for Vaasa harbour grid connection. Section III provides a methodology of developing a control algorithm for battery energy storage system in Vaasa harbour grid which aims for charging and discharging battery energy storage system based on shaving off the peak-load demand while considering the power constrains. A case study has been considered by employing real grid data of hourly annual power consumption of the secondary substations to control power and energy for Vaasa harbour grid. The simulation results are discussed in Section IV, and the conclusion is presented in Section V.

\section{Simulation Model of VAasa harbour Grid}

This section introduces the simulation model of Vaasa harbour grid based on real data obtained from the local distribution system operator Vaasan Sähköverkko and harbour operator Kvarken port of Vaasa. First, the detailed single line diagram of Vaasa harbour grid topology is presented and then based on that the Vaasa harbour grid model is developed using MATLAB Simulink.

\section{A. Vaasa harbour grid topology}

The single line diagram in Fig. 1 shows the detailed feeder topology of Vaasa harbour, where the power is being supplied from Vaasa electric supply. The $20 \mathrm{kV}$ medium voltage (MV) main feeder named J08 is supplied from the $110 \mathrm{kV}$ transmission grid through a primary transformer of $110 / 20$ $\mathrm{kV}$. This $\mathrm{J} 08$ feeder supplies several secondary substations named as $4697,630,666,59,55$, and 8017 . Now, the new secondary substation named 4949 is under construction for enabling the shore to ship power supply to the new hybrid electric ferry. At present only this ferry is considered for shore to ship power supply and maximum power demand is assumed to be $2 \mathrm{MW}$, while the duration of shore to ship power supply depends on the cruising schedules. In reality there will be four connection points for the ferry in the quay, and interlocking switch is placed in such a way that enables various ways of docking with the integration of battery energy storage system as shown in Fig. 1. This new hybrid electric ferry will travel in the route between Vaasa and Umeå as shown in Fig.2 (Geographical map).

\section{B. Simulation model in MATLAB Simulink}

The single line diagram in Fig. 1 has been modelled in MATLAB Simulink as shown in Fig. 3. The real data obtained for each component such as for transformers, conductors (cables), hourly load profile of each secondary substation has been employed in the model. The new connection at 4949 secondary substation for Vaasa harbour grid will provide shore to ship power supply to the new ferry which will have a fixed schedule of arriving and leaving the seaports. Therefore, keeping in view the schedule of new ferry, load profile for onshore power supply at that node (4949) has also been calculated and its data has been employed in the MATLAB Simulink model. It has been observed that there is certain time, where the peak-load demand is high and may not be supplied with the current carrying power capacity of the MV feeder and power transformers. Therefore to shave the peakload demand, a suitable size of battery is designed in such a way that it charges during off-peak load demand and discharge during peak-load demand. The bi-directional AC/DC converter is connected in between $\mathrm{AC}$ bus of $0.69 \mathrm{kV}$ and battery energy storage system, which is used to charge/discharge the battery depending upon power requirements. Thus, the proposed methodology of controlling the battery energy storage is based on real data of harbour grid and the schedule of shore to ship power supply and it aims to keep the power obtained from the grid within the capacity limits by charging and discharging the battery.

\section{THE PROPOSED METHODOLOGY}

Vaasa harbour grid plans onshore power supply for new ferry and the schedule of the vessels staying at seaports determine the peak-load demand of harbour grids. This paper aims to develop control algorithm for charge/discharge cycle of the battery energy storage system for Vaasa harbour grid to cope with peak-load demand economically. Moreover, power and energy management of the harbour grids can be well tackled by avoiding extra burden on the existing power infrastructure such as: power cables and, power transformers. First of all, the developed model is simulated in MATLAB Simulink without designing the battery energy storage system for it. Then it has been observed that the peak-load demand of the harbour is higher than the existing rating of electrical infrastructure, such as rating of the transformers and cables. The mismatch of maximum load demand and normal ratings of the equipment are decisive factor for designing an appropriate size of the battery energy storage system. Afterwards, the daily, weekly, monthly and yearly energy demand of Vaasa harbour grid is calculated for determining charge/discharge cycle of the battery. As the energy demand is different at different time depending upon schedule of shore to ship power, which varies at different days and season of the year. Therefore, energy demand is decisive in charge/discharge cycle of the battery energy storage system. The size of BESS and charge/discharge cycle are considered in such a way that the renovating of MV feeder is avoided and the peak-load demand is met without violating HVSC standard requirement of voltage limits.

The following equations are used to calculate the size of the battery energy storage system:

$$
\begin{aligned}
& \mathrm{P}_{\text {grid }}+\mathrm{P}_{\text {battery }}=\mathrm{P}_{\text {demand }} \\
& \mathrm{P}_{\text {demand }}=\mathrm{P}_{\text {harbour }}+\mathrm{P}_{\mathrm{S} 2 \mathrm{~S}} \\
& \text { Constraint: } \mathrm{P}_{\text {grid }} \leq 2.5 \mathrm{MW}
\end{aligned}
$$




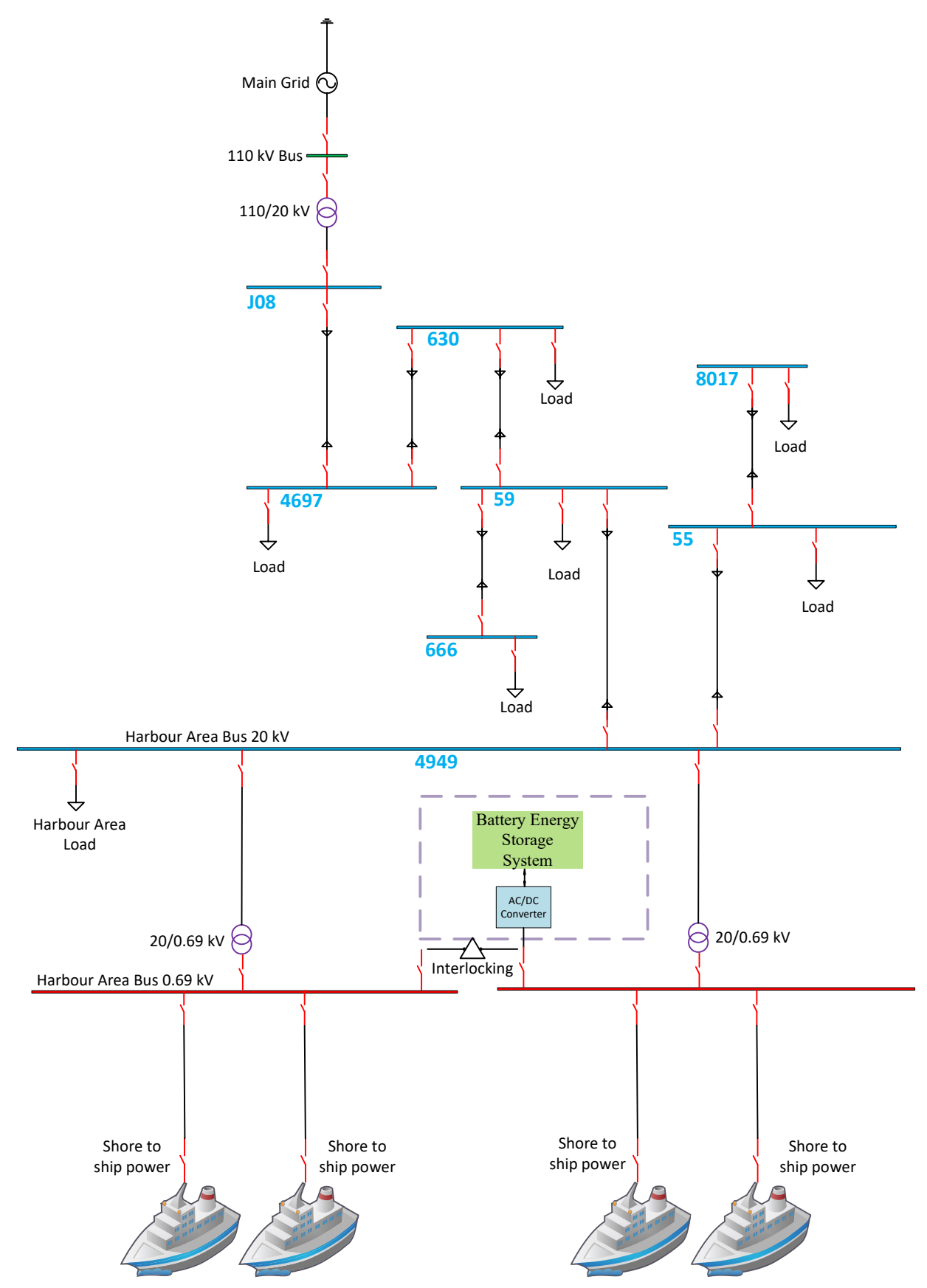

Fig. 1. Feeder topology of Vaasa harbour

Where $\mathrm{P}_{\text {grid }}$ is power from the grid, $\mathrm{P}_{\text {battery }}$ is power supplied by the battery, $\mathrm{P}_{\text {demand }}$ is total power demand at harbour, $\mathrm{P}_{\text {harbour }}$ is harbour load, and $\mathrm{P}_{\mathrm{S} 2 \mathrm{~S}}$ is shore to ship power. The energy storage capacity for the battery energy storage has been designed with the following constrains:

$$
\begin{aligned}
& 20 \% \leq \mathrm{SOC} \geq 100 \% \\
& \mathrm{SOC} \leq 0.2 \mathrm{C}
\end{aligned}
$$

The following flow chart in Fig. 4 shows the control algorithm for an energy management system of the proposed methodology. It shows that battery is charged between $20-100 \%$ whenever the power demand is less than grid power and it is discharged whenever power demand is higher than grid power and battery has state of charge (SOC) between $20-100 \%$. In all, other cases battery is in idle mode of

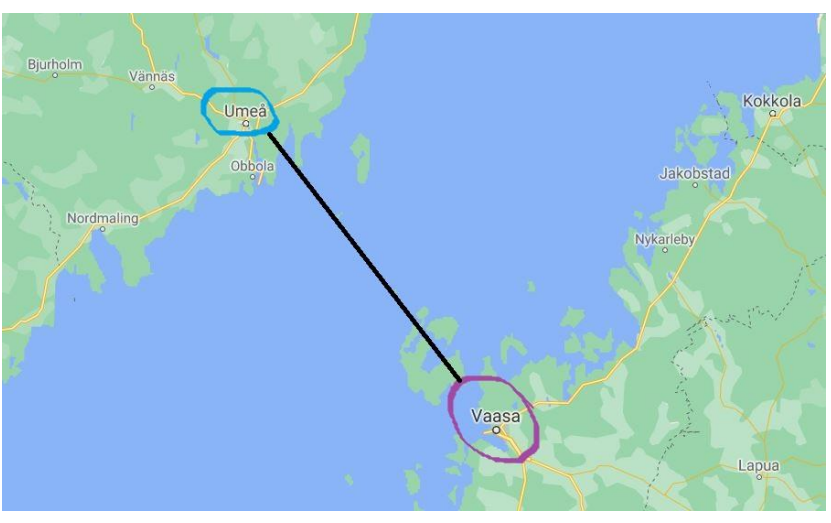

Fig. 2. Ferry route of Vaasa-Umeå 


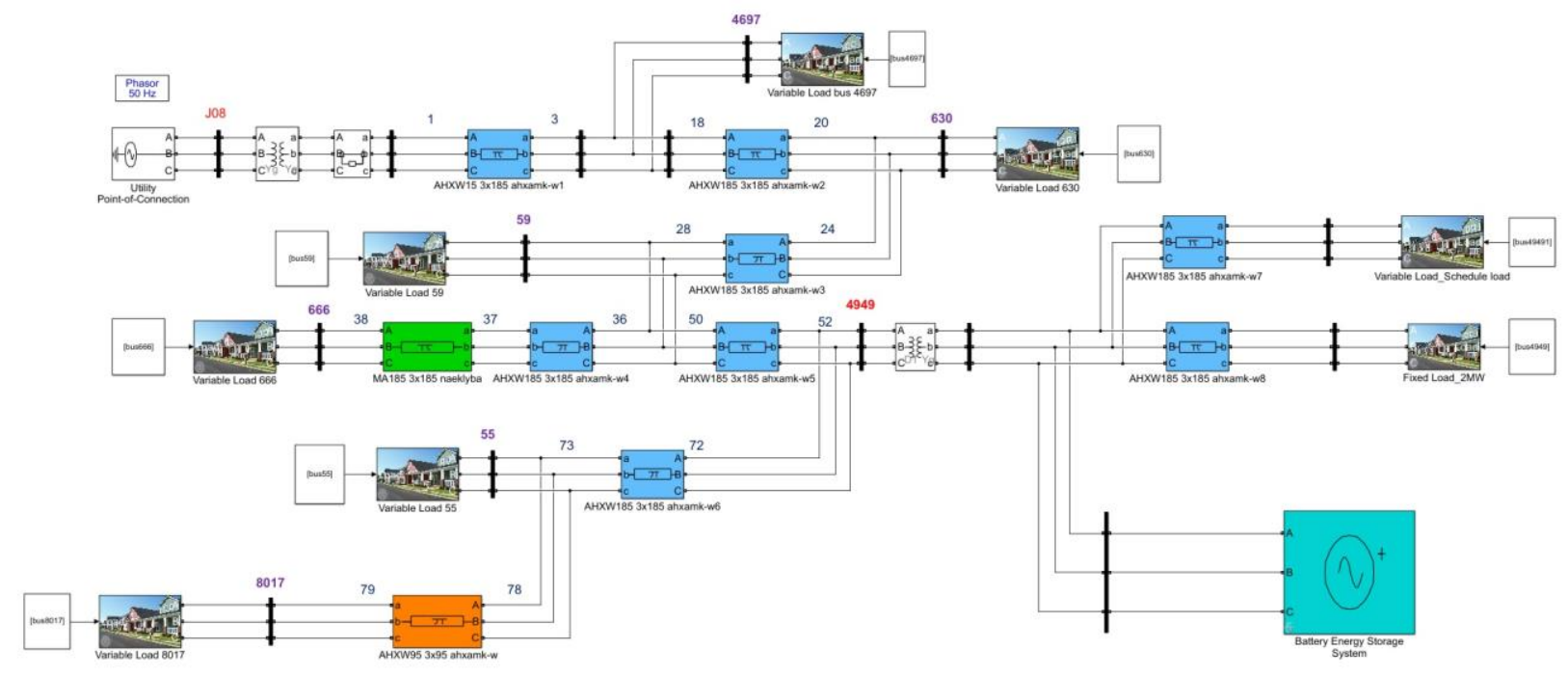

Fig. 3. Simplified MATLAB Simulink Model of the proposed power system

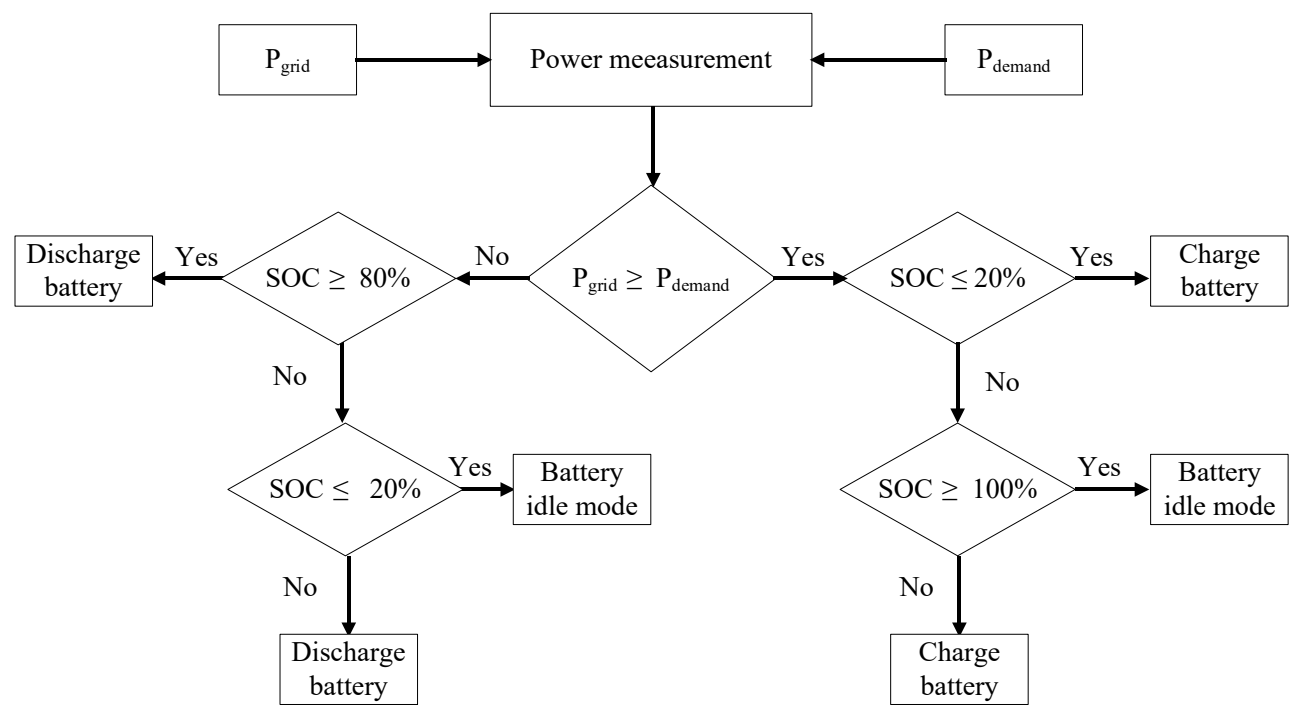

Fig. 4. Control algorithm of energy management system

operation because it is recommended to not to discharge lithium ion battery over $80 \%$ depth of discharge. The sizing of battery energy storage has been designed in such a way that battery is charged or discharged throughout the operation and idle mode of operation is avoided especially when power demand is higher than power being supplied by the grid.

\section{Results}

The simulation results are shown in Fig. 5, Fig. 6, and Fig. 7. They are obtained by integrating proper size of battery energy storage system into Vaasa harbour grid and implementing charging and discharging the battery according to the developed algorithm.

The Fig. 5 shows the grid power, load power and battery power. The maximum load demand of Vaasa harbour grid is $4 \mathrm{MW}$ at certain times of the year depending upon schedule of onshore power supply, whereas the harbour grid has the limited power capacity of $2.5 \mathrm{MW}$ from the grid.
Therefore, the extra power is being supplied by the battery in such a way that peak-load demand of harbour grid is shaved off. It represents that whenever the load demand is higher than the grid power, then the battery power is being supplied by discharging the battery. Whenever, the power demand of the load is less than the grid power, then the battery is being charged. Thus, the applied control algorithm performs well and the net power, which is difference of grid power and demand power is utilised in terms of charge/discharge cycle of battery depending upon power requirement of harbour grid.

The Fig. 6 shows the graph of state of charge (SOC) and power being charged or discharged by the battery. It shows that whenever battery is being charged, the SOC increases, and the power is being absorbed by the battery as shown negative power in the graph. On other hand, whenever the battery is being discharged, the SOC decreases, and power is being supplied by the battery as shown positive 


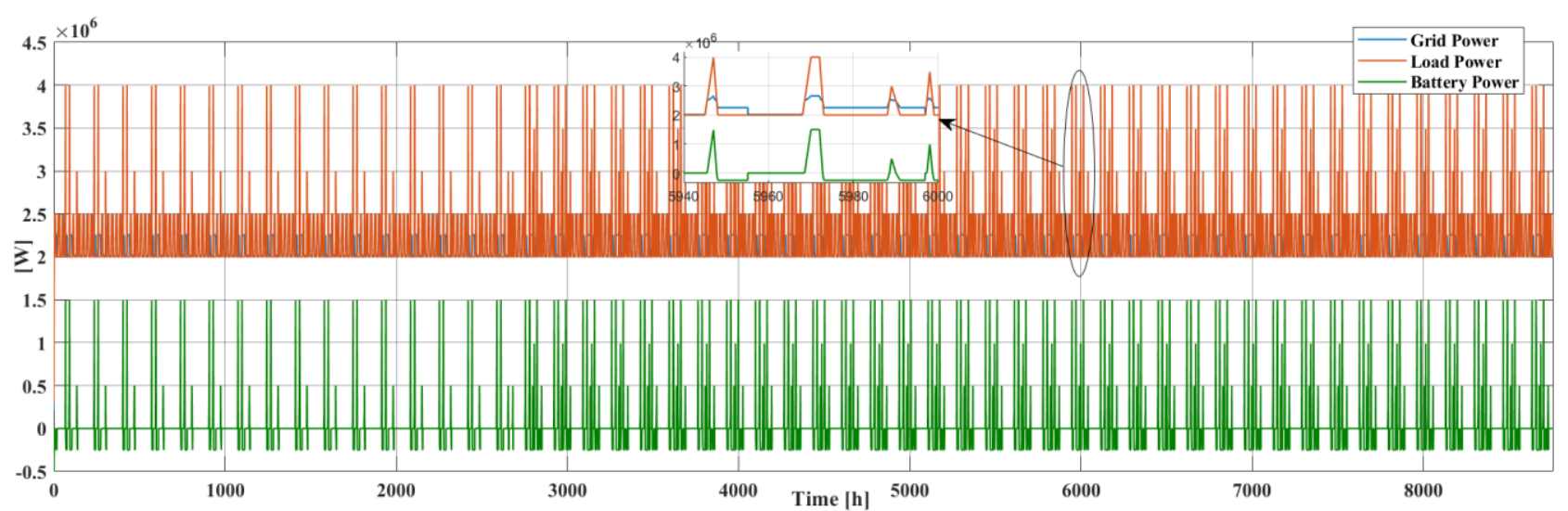

Fig.5. Grid power, load power and battery power
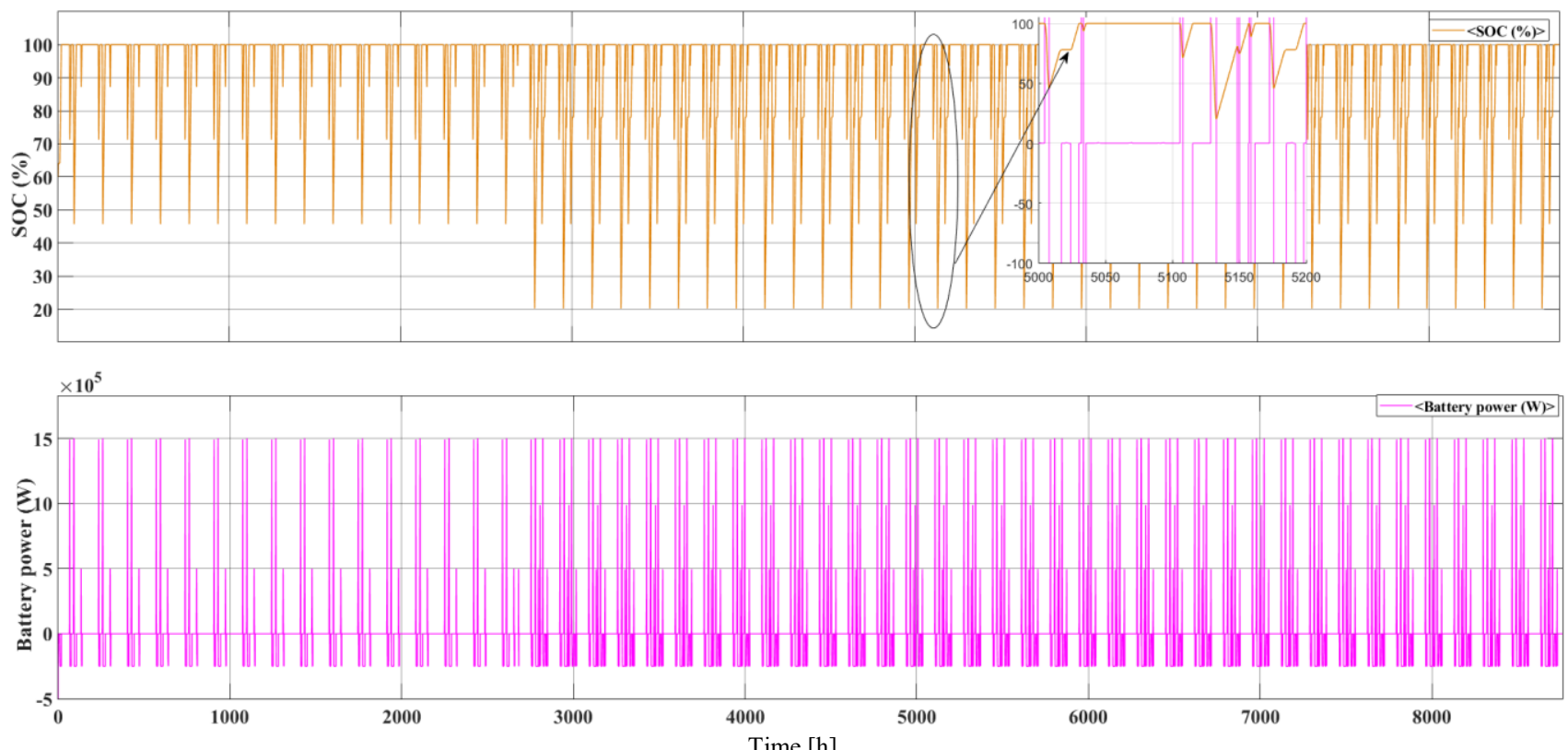

Fig. 6. State of charge and charge/discharge of battery

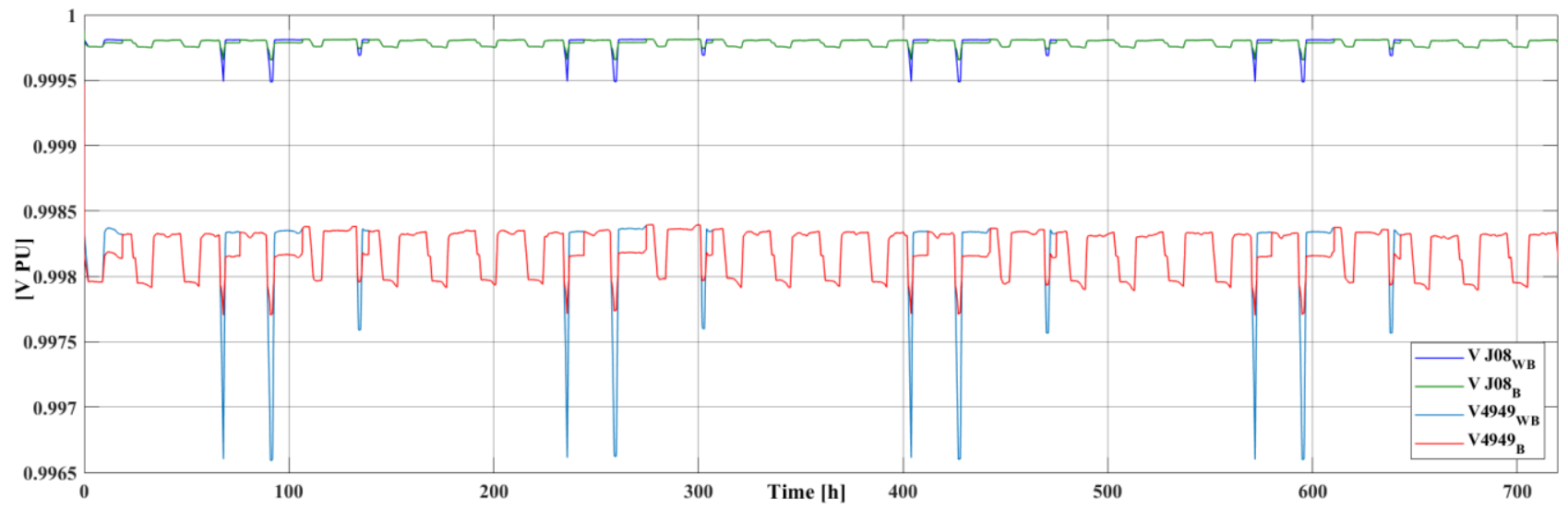

Fig. 7. Voltage profile at secondary substations without and with battery 
power in the graph. The battery is in idle mode of operation, when $\mathrm{SOC}=100 \%$ and load demand is also less than the power being supplied by the grid. It is also due to the fact that the main objective of this research paper is to shave peak-load demand and therefore this limits to further reduce the size of battery energy storage system because of variable nature of load profile. The battery energy storage system is designed in such a way that it has also constant charging current so that the idle time can be minimized as much as possible.

The voltages at secondary substations are also within limits as described by the HVSC standards. It has been observed that voltages at all the secondary substations are within the specified limits at all over the year. Moreover with the integration of battery energy storage system, voltage profiles at all the buses have been further improved. The results of voltage profile of two main buses (J08 and 4949) in per unit have been shown in Fig. 7 for the sample time of one month.

The results are obtained by doing multiple simulations in order to keep the idle time and size of the battery as minimum as possible to cope with peak-load power demand of harbour. However, the major concern was the schedule of the ferries requiring suddenly high amount of power in short interval of time. Due to this, the idle time and size of the battery energy storage system can not be further reduced.

\section{CONCLUSION AND FUTURE WORK}

This paper illustrated how the power and energy demand of the harbour grid may vary at different time of the day, different season of the year and so on. It mainly depends upon the schedule of shore to ship power supply of the new hybrid electric ferry. It might be challenging to cope with the high power demand during peak-load of modern harbour grids with the available electrical infrastructure. Therefore, battery energy storage can play a significant role for stable and reliable operation of the harbour grid. It has been concluded through a case study of Vaasa harbour grid that capital cost on electrical equipment such as transformers, cables etc. can be avoided by employing an appropriate size of battery energy storage system and power demand can be controlled by charge/discharge cycle of battery energy storage system. Thus, modern harbour grids in future can employ the proposed methodology and control power and energy requirement with the predetermined load profile data.

In future, the developed model can be utilised when considering the integration of renewables and battery charging system to the Vaasa harbour grid. Then the smart control and optimisation techniques can be further developed to minimise the operational cost of power consumption. The optimal design of the battery storage device can be determined with by employing some suitable decision-making model. This could be achieved by integrating forecasting methods to anticipate peak load periods. The trade-off between the size of the battery and the profitability of the investment can also be compared to the load peaks frequency.

\section{REFERENCES}

[1] IMO, "Second IMO GHG study 2009. London: International Maritime Organization," 2009.

[2] D. Kumar and F. Zare, "A Comprehensive Review of Maritime Microgrids: System Architectures, Energy Efficiency, Power Quality, and Regulations," IEEE Access, vol. 7, pp. 67249-67277, 2019, doi: 10.1109/ACCESS.2019.2917082.

[3] C. Nuchturee, T. Li, and H. Xia, "Energy efficiency of integrated electric propulsion for ships - A review," Renewable and Sustainable Energy Reviews, vol. 134. Elsevier Ltd, p. 110145, Dec. 01, 2020, doi: 10.1016/j.rser.2020.110145

[4] J. Kumar, O. Palizban, and K. Kauhaniemi, "Designing and analysis of innovative solutions for harbour area smart grid," Jul. 2017, doi: 10.1109/PTC.2017.7980870.

[5] J. Kumar, L. Kumpulainen, and K. Kauhaniemi, "Technical design aspects of harbour area grid for shore to ship power: State of the art and future solutions," International Journal of Electrical Power and Energy Systems, vol. 104. Elsevier Ltd, pp. 840-852, Jan. 01, 2019, doi: 10.1016/j.ijepes.2018.07.051.

[6] J. Kumar, C. Parthasarathy, M. Västi, H. Laaksonen, M. Shafie-Khah, and K. Kauhaniemi, "Sizing and Allocation of Battery Energy Storage Systems in Åland Islands for Large-Scale Integration of Renewables and Electric Ferry Charging Stations," Energies, vol. 13, no. 2, p. 317, Jan. 2020, doi: 10.3390/en13020317.

[7] E. A. Sciberras, B. Zahawi, and D. J. Atkinson, "Electrical characteristics of cold ironing energy supply for berthed ships," Transp. Res. Part D Transp. Environ., vol. 39, pp. 31-43, Aug. 2015, doi: $10.1016 / j$.trd.2015.05.007.

[8] IEC/ISO/IEEE 80005-1, Utility connections port-Part 1: HIgh Voltage Shore Connection (HVSC) Systems-General requirements. IEC/ISO/IEEE International Standard, 2012.

[9] T. Coppola, M. Fantauzzi, D. Lauria, C. Pisani, and F. Quaranta, "A sustainable electrical interface to mitigate emissions due to power supply in ports," Renew. Sustain. Energy Rev., vol. 54, pp. 816-823, Feb. 2016, doi: 10.1016/j.rser.2015.10.107.

[10] B. Stolz, M. Held, G. Georges, and K. Boulouchos, "The CO2 reduction potential of shore-side electricity in Europe," Appl. Energy, vol. 285, p. 116425, Mar. 2021, doi: 10.1016/j.apenergy.2020.116425.

[11] Directive 2005/33/EC Of the European Parliament and of the Council. Official Journal of the European Union, 2005.

[12] J. Prousalidis, G. Antonopoulos, C. Patsios, A. Greig, and R. Bucknall, "Green shipping in emission controlled areas: Combining smart grids and cold ironing," in 2014 International Conference on Electrical Machines (ICEM), Sep. 2014, pp. 2299-2305, doi: 10.1109/ICELMACH.2014.6960506.

[13] E. Skjong, T. A. Johansen, M. Molinas, and A. J. Sorensen, "Approaches to Economic Energy Management in Diesel-Electric Marine Vessels," IEEE Trans. Transp. Electrif., vol. 3, no. 1, pp. 22 35, Mar. 2017, doi: 10.1109/TTE.2017.2648178.

[14] K. Hein, Y. Xu, W. Gary, and A. K. Gupta, "Robustly coordinated operational scheduling of a grid-connected seaport microgrid under uncertainties," IET Gener. Transm. Distrib., vol. 15, no. 2, pp. 347358, Jan. 2021, doi: 10.1049/gtd2.12025.

[15] S. Fang, Y. Wang, B. Gou, and Y. Xu, "Toward Future Green Maritime Transportation: An Overview of Seaport Microgrids and All-Electric Ships," IEEE Transactions on Vehicular Technology, vol. 69, no. 1. Institute of Electrical and Electronics Engineers Inc., pp. 207-219, Jan. 01, 2020, doi: 10.1109/TVT.2019.2950538.

[16] H. S. Khan, M. Aamir, K. Kauhaniemi, M. Mumtaz, M. W. Hassan, and M. Ali, "Improved finite control set model predictive control for distributed energy resource in islanded microgrid with fault-tolerance capability," Eng. Sci. Technol. an Int. J., vol. 24, no. 3, pp. 694-705, Jun. 2021, doi: 10.1016/j.jestch.2020.12.015

[17] A. Roy, F. Auger, J.-C. Olivier, E. Schaeffer, and B. Auvity, "Design, Sizing, and Energy Management of Microgrids in Harbor Areas: A Review," Energies, vol. 13, no. 20, p. 5314, Oct. 2020, doi: 10.3390/en13205314. 